\title{
Exercise-Associated Changes in the Corticosterone Response to Acute Restraint Stress: Evidence for Increased Adrenal Sensitivity and Reduced Corticosterone Response Duration
}

\author{
Brendan D Hare', Jacob A Beierle', Donna J Toufexis', Sayamwong E Hammack' and William A Falls*,' \\ 'Department of Psychology, University of Vermont, Burlington, Vermont, USA
}

\begin{abstract}
Exercise promotes stress resistance and is associated with reduced anxiety and reduced depression in both humans and in animal models. Despite the fact that dysfunction within the hypothalamic pituitary adrenal (HPA) axis is strongly linked to both anxiety and depressive disorders, the evidence is mixed as to how exercise alters the function of the HPA axis. Here we demonstrate that 4 weeks of voluntary wheel running was anxiolytic in C57BL/6) mice and resulted in a shorter time to peak corticosterone (CORT) and a more rapid decay of CORT following restraint stress. Wheel running was also associated with increased adrenal size and elevated CORT following systemic administration of adrenocorticotropic hormone. Finally, the HPA-axis response to peripheral or intracerebroventricular administration of dexamethasone did not suggest that wheel running increases HPA-axis negative feedback through GR-mediated mechanisms. Together these findings suggest that exercise may promote stress resilience in part by insuring a more rapid and shortened HPA response to a stressor thus affecting overall exposure to the potentially negative effects of more sustained HPA-axis activation. Neuropsychopharmacology (2014) 39, 1262-1269; doi:I0.1038/npp.2013.329; published online I8 December 2013
\end{abstract}

Keywords: anxiety; corticosterone; exercise; glucocorticoids; HPA; stress

\section{INTRODUCTION}

Voluntary wheel running has been shown to promote stress resistance, a reduced response to stressor exposure, in humans (Broocks et al, 2001) and rodents (Greenwood et al, 2005; Greenwood et al, 2003). In humans, exercise is associated with a reduced incidence of stress-related psychopathology (De Moor et al, 2006; Dunn et al, 2001; Herring et al, 2010; Lawlor and Hopker, 2001), and in rodents, voluntary wheel running is associated with reduced anxiety- and depression-like behaviors (Binder et al, 2004; Fox et al, 2008; Greenwood et al, 2005; Greenwood et al, 2003; Salam et al, 2009; Sciolino et al, 2012). For example, we have shown that 2 weeks of home cage wheel running in C57BL/6J mice reduces acoustic startle amplitude, reduces stress-induced hyperthermia, diminishes anxiety-like behavior in the open field, and reduces the anxiogenic effect of the serotonin agonist $\mathrm{m}$-chlorophenylpiperazine (mCPP, Fox et al, 2008; Salam et al, 2009).

Dysfunction within the hypothalamic pituitary adrenal (HPA) axis, often assessed through measurement of the HPA-axis end product corticosterone (CORT), is a hallmark

* Correspondence: WA Falls, Department of Psychology, University of Vermont, John Dewey Hall, 2 ColcehsterAvenue, Burlington, Vermont 05405, USA, Tel: + I 802656 5748, Fax: + | 8026568783 ,

E-mail: william.falls@uvm.edu

Received 2 October 2013; revised 18 November 2013; accepted 20 November 2013; accepted article preview online 26 November 2013 of many stress-related psychopathologies (de Kloet et al, 2005; Holsboer, 2001; Kellner et al, 1997; Yehuda et al, 1998). Wheel running also changes HPA-axis function; for example, wheel running produces elevated CORT at the onset of the diurnal active period in both rats and mice (Adlard and Cotman, 2004; Droste et al, 2003; Fediuc et al, 2006; Stranahan et al, 2006) and is consistently associated with enlarged adrenals (Campeau et al, 2010; Droste et al, 2007; Droste et al, 2003; Droste et al, 2006; Nyhuis et al, 2010; Sasse et al, 2008). The HPA-axis response to both acute (Campbell et al, 2009; Campeau et al, 2010; Droste et al, 2007; Droste et al, 2003; Droste et al, 2006) and repeated (Nyhuis et al, 2010; Sasse et al, 2008) stress is also altered in wheel-running rodents. Thus, the changes observed in HPA-axis outcomes following wheel running mirror those of chronic stress in some cases (adrenal enlargement, diurnal CORT), and demonstrate stress resistance in others (response to stress).

Exercise-associated changes in the HPA-axis response to stress could be the result of changes in CORT release, CORT response termination, or both. Changes in CORT release from the adrenals could result from changes in adrenal sensitivity to adrenocorticotropic hormone (ACTH), or changes in the release of ACTH from the pituitary (Cone et al, 1993). Although several studies have found adrenal enlargement in wheel-running rodents, few studies have directly assessed whether the enlargement leads to increased adrenal sensitivity to ACTH (see Campbell et al, 2009). One 
mechanism by which termination of CORT release from the adrenals may be achieved is through glucocorticoid receptor (GR)-mediated negative feedback at multiple sites, including the hippocampus and pituitary (Herman et al, 2005). Indeed, studies have shown that GR expression in wheel-running mice is altered leading to the possibility that enhanced negative feedback following HPA-axis activation may be expected (Droste et al, 2003). However, to our knowledge, no study has assessed whether wheel running alters negative feedback in the HPA axis.

The goals of the current study are to investigate whether voluntary wheel running in mice alters the time course of the CORT response to restraint stress, and whether these changes are associated with altered sensitivity to ACTH and/or GR-mediated enhancement of negative feedback within the HPA axis.

\section{MATERIALS AND METHODS}

\section{Subjects}

Six-week-old male C57BL/6J mice were obtained from Jackson Laboratories (Bar Harbor, Maine) and housed for a 14-day acclimation period prior to the start of all experiments. Mice were housed in groups of four in standard acrylic cages $(24 \mathrm{~cm}(\mathrm{~W}) \times 45 \mathrm{~cm}(\mathrm{D}) \times 20 \mathrm{~cm}(\mathrm{H}))$ in an Association for Assessment and Accreditation of Laboratory Animal Care (AAALAC) approved conventional animal facility for the duration of the experiment. Mice were maintained on a 12-h light/dark cycle (lights on at 0700 hours (ZT0)) with ad lib access to food and water. All procedures were approved by the University of Vermont Animal Care and Use Committee. All mice provided wheel access (running) had $a d$ lib access to a running wheel for the full duration of the study following baseline startle testing.

\section{Startle Testing}

A baseline (pre-wheel access) acoustic startle test was conducted as previously described (Salam et al, 2009). The mean startle amplitude for each mouse across the 30 trial tests was computed for use in statistical analyses. Startle was again assessed on days 14 and 28. Startle testing was conducted in all mice prior to HPA-axis manipulations.

\section{Blood Collection and CORT Assay}

All blood was obtained by cutting a small portion of the tail $(2 \mathrm{~mm})$ and drawing down gently on the tail to collect blood into EDTA-coated centrifuge tubes. Approximately $100 \mu \mathrm{l}$ of blood was collected from each animal and immediately centrifuged (3000 r.p.m., $4^{\circ} \mathrm{C}$ ). Blood plasma was collected and stored at $-20^{\circ} \mathrm{C}$ until processing. For CORT assessment, plasma was heated at $75^{\circ} \mathrm{C}$ for $1 \mathrm{~h}$ to disassociate CORT from CORT binding globulin (Buck et al, 2011). Following heat treatment, samples were processed using a broad-spectrum CORT enzyme immunoassay (Enzo Scientific, Farmingdale, NY, detection limit $27 \mathrm{pg} / \mathrm{ml}$ ) per the manufacturer's instructions. The interassay coefficient of variance was $9.66 \%$.

\section{Experiment 1}

Experiment 1 was designed to examine the CORT response to restraint stress in wheel-running and sedentary mice. Running mice $(n=62)$ were given $a d$ lib wheel access for 28 days prior to restraint testing to match the access period used in previous studies of HPA-axis function (Droste et al, 2003; Droste et al, 2006); sedentary mice $(n=62)$ did not have wheel access.

\section{Restraint Stress}

Mice were restrained in $50 \mathrm{ml}$ centrifuge tubes modified to allow for air circulation for $30 \mathrm{~min}$. Blood was collected via tail cut prior to $(0 \mathrm{~min})$, during $(10,20$, and $30 \mathrm{~min})$, and following (60 $\mathrm{min}, 90 \mathrm{~min}, 120 \mathrm{~min}$ ) restraint stress using a between-subjects design.

\section{Active-Phase CORT Measurement}

On days 14 and 28, a subset of mice used in the restraint stress study were utilized to assess CORT at the onset of the active phase (ZT12, $n=8$ per group) as elevated CORT levels have been observed at this time point in wheelrunning animals (Adlard and Cotman, 2004; Droste et al, 2003; Fediuc et al, 2006). A second subset of mice ( $n=8$ per group) was also sampled $1 \mathrm{~h}$ into the active phase of the light cycle (ZT13) to ensure that exercising animals had sufficient time to engage in activity prior to sampling.

\section{Assessment of Organ Weight}

Following restraint, a subset of the mice ( $n=38$ per group) were utilized for assessment of adrenal and thymus weight by an experimenter blind to experimental condition. The thymus and adrenals were removed from each mouse and defatted prior to being weighed.

\section{Experiment 2}

Experiment 2 examined CORT suppression following administration of the synthetic GR agonist, dexamethasone, in running and sedentary mice. Following baseline startle testing mice were assigned to sedentary $(n=50)$ and running $(n=50)$ groups. Startle amplitude from four running and four sedentary mice were not analyzed due to equipment malfunction during the baseline startle measure; however, these animals were included in the central DST analysis.

\section{Peripheral Dexamethasone Suppression Test}

Peripheral HPA-axis negative feedback was assessed following an ip injection of dexamethasone $(0.0,0.01$, and $0.05 \mathrm{mg} / \mathrm{kg}$, Sigma-Aldrich, St Louis, MO, dissolved in ethanol prior to $\mathrm{dH}_{2} \mathrm{O}$ dilution ( $2 \%$ ethanol by volume)) in a within-subjects design ( $n=20$ running, $n=19$ sedentary). The peripheral DST took place over a 5-day period with injections occurring on days 1, 3, and 5. Dose was randomly assigned by cage such that each cage received each of the three doses over the three test days. Blood samples were collected $6 \mathrm{~h}$ after dexamethasone administration as described previously (Bartolomucci et al, 2004; Groenink et al, 
2002; Robertson et al, 2005). Mice with plasma CORT values greater than $3 \mathrm{SD}$ from the mean at each concentration within each group were removed from analysis (four exercising and three sedentary mice).

\section{Central Dexamethasone Suppression Test}

Dexamethasone does not readily cross the blood-brain barrier (Cole et al, 2000). In order to examine whether there were changes in GR-associated feedback inhibition of the HPA-axis mediated by regions within the central nervous system, we infused dexamethasone into the cerebral ventricles (ICV, central). Central negative feedback within the HPA axis was assessed in a between-subjects design ( $n=30$ running, $n=31$ sedentary). Dexamethasone $(0.04 \%$ ethanol by volume) was administered using an acute and rapid ICV injection technique described previously (Pelleymounter et al, 2000; Risbrough et al, 2004). For the acute ICV injections, mice were lightly anesthetized with isoflurane and a 30-gauge needle affixed to a $10 \mu \mathrm{l}$ Hamilton syringe was inserted through the skin and skull and into the lateral ventricle at a site identified as the apex of an equilateral triangle with its base between the eyes. The needle was fitted with a plastic sleeve as a 'stop' in order to achieve a $4.0 \mathrm{~mm}$ injection depth. Dexamethasone $(0 \mathrm{ng}$, $1 \mathrm{ng}, 2 \mathrm{ng}$; in $2 \mu \mathrm{l}$ ) was slowly infused over a period of $10 \mathrm{~s}$. Blood was collected $4 \mathrm{~h}$ after dexamethasone administration. Immediately following blood sampling, mice were anesthetized and rapidly decapitated. Injection sites were localized by placing a drop of cresyl violet onto the injection site of overlying cortex. A coronal cut was then made at the injection site. Cresyl violet staining through the injection track into the ventricle verified a successful injection. A single exercising mouse and a single sedentary mouse were removed from the central DST analysis due to blood in the ventricle and missed injection location, respectively.

\section{Peripheral and Central Dexamethasone Suppression Test with an Intermediate Dose}

Because the low dose of dexamethasone $(0.01 \mathrm{mg} / \mathrm{kg}$ ip, $1 \mathrm{ng}$ ICV) failed to produce suppression while the high doses $(0.05 \mathrm{mg} / \mathrm{kg}$ ip, $1.5 \mathrm{ng} \mathrm{ICV})$, produced complete suppression, a second cohort of animals $(n=16$ ip, $n=16 \mathrm{ICV}, 8$ animals per group) were examined at an intermediate dose of dexamethasone $(0.025 \mathrm{mg} / \mathrm{kg}$ ip, $1.5 \mathrm{ng} \mathrm{ICV})$.

\section{Experiment 3}

The results of Experiment 1 demonstrated that the rise time of the CORT response to restraint stress was more rapid, which may have been mediated by increased adrenal sensitivity, and is notable given the observation that wheel running has been associated with increased adrenal size (Campeau et al, 2010; Droste et al, 2007; Droste et al, 2003; Droste et al, 2006; Nyhuis et al, 2010; Sasse et al, 2008). Experiment 3 directly assessed whether the CORT response to exogenous ACTH challenge was increased in running mice. Following acclimation to the colony, mice underwent startle testing and were assigned to running $(n=16)$ and sedentary $(n=16)$ groups. Two sedentary mice and one running mouse were removed from startle analysis due to equipment malfunction.

\section{ACTH Challenge}

Twenty-four hours after the 28-day startle test, mice were challenged with either a low ( $5 \mu \mathrm{g} / \mathrm{kg}$ ip, $n=8$ per group) or high $(50 \mu \mathrm{g} / \mathrm{kg}$ ip, $n=8$ per group) dose of ACTH (SigmaAldrich, St Louis, MO, dissolved in saline). Prior to ACTH challenge, blood was sampled at 0800 hours to establish a baseline level of CORT. Mice were then given an injection of dexamethasone $(0.05 \mathrm{mg} / \mathrm{kg})$ in order to limit endogenous ACTH release (Dijkstra et al, 1996; Han et al, 1998; Michopoulos et al, 2012; Otsuka et al, 2012). This dose of dexamethasone was chosen as it exhibited equivalent CORT suppression in both groups following peripheral administration in Experiment 2. Four hours after the dexamethasone injection, blood collection was immediately followed by ACTH injection. Blood was again collected 30 and $90 \mathrm{~min}$ after the ACTH injection. Mice remained in the laboratory during the course of the ACTH challenge.

\section{Statistical Analysis}

Startle results were assessed using a mixed model ANOVA with test day as the within-subject factor and group as the between-subject factor. Significant interactions were followed by paired sample $t$-tests. Restraint stress CORT measurements were analyzed by two-way (group X time) ANOVAs followed by lower-order ANOVAs and independent sample $t$-tests. Adrenal and thymus weights were calculated as a percentage of body weight and compared using independent sample $t$-tests. Active-phase CORT measurements in Experiment 1 were analyzed using two-way (day $\mathrm{X}$ group) ANOVAs for each time point. Peripheral DST results were assessed using a mixed model ANOVA with dose as the within-subject factor and group as the between-subject factor. Central DST results were assessed using a two-way (group $\mathrm{X}$ dose) ANOVA. Significant main effects were followed by paired (peripheral DST) and independent (central DST) sample $t$-tests. To avoid confounding animal cohorts, results from second cohort central and peripheral DSTs were analyzed separately. Second cohort peripheral DST results were assessed using a mixed model ANOVA with dose as the within-subject factor and group as the between-subject factor. Second cohort central DST results were analyzed by independent sample $t$-test. High-dose and low-dose ACTH challenge results were analyzed separately using mixed model ANOVAs with group as the between-subject factor and time as the within-subject factor. The ANOVA was followed by independent sample $t$-tests.

\section{RESULTS}

\section{Experiment 1}

Acoustic startle. Wheel running resulted in reduced startle amplitude in mice given 4 weeks access to a running wheel (Figure 1). Significant main effects of startle day $(\mathrm{F}(2,244)=26.36, p<0.001)$, and group $(\mathrm{F}(1,122)=6.04$, $p<0.01$ ), were qualified by a significant interaction (day X group $\mathrm{F}(2,244)=12.76, p<0.001)$. Only in running mice 


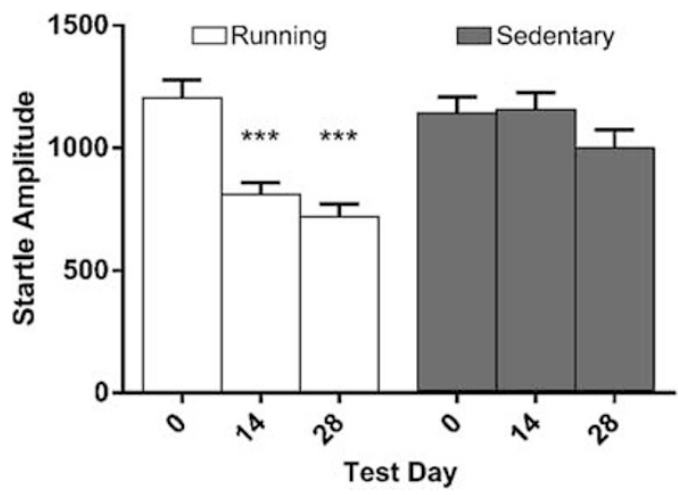

Figure I Mean startle amplitude (arbitrary unit \pm SEM) during the 4-week wheel-running period in Experiment I. Running mice demonstrated reduced startle amplitude compared with baseline on days 14 and 28 of wheel access. $* * * * 0<0.001$ in comparison with respective test day 0 .

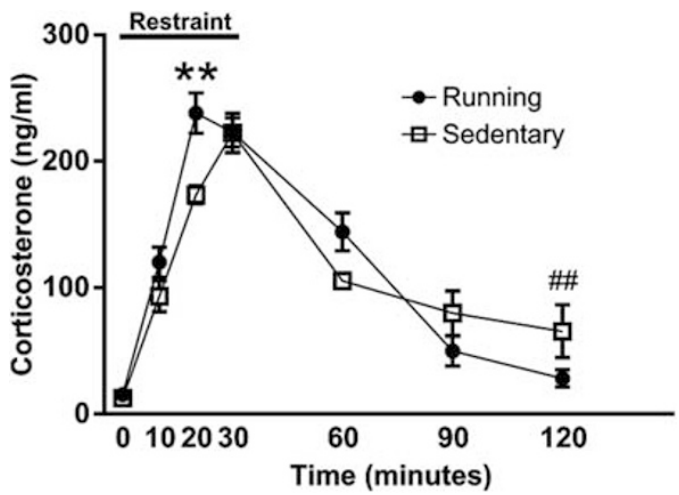

Figure 2 Mean plasma corticosterone concentrations ( $\mathrm{ng} / \mathrm{ml} \pm \mathrm{SEM}$ ) during restraint stress procedure. Running mice demonstrated an elevated response compared with sedentary animals at $20 \mathrm{~min}$, and also returned to baseline more rapidly. $* * * 0.01$ running in comparison with sedentary at time 20. ${ }^{\# \#} p<0.01$ sedentary time 120 in comparison with sedentary time 0 .

was startle amplitude reduced compared with baseline (prewheel access) levels. Running mice demonstrated reduced startle amplitude at day $14(t(61)=6.77, p<0.001)$, and 28 $(t(61)=7.03, p<0.001)$.

Restraint stress response. Restraint produced a CORT response in both sedentary and running mice (time, $\mathrm{F}(6,114)=111.04, p<0.001$, Figure 2). The main effect of time interacted significantly with group (time $\mathrm{X}$ group, $\mathrm{F}(6,114)=4.92, \quad p<0.001)$. The peak CORT response observed in running and sedentary mice did not differ $(t(14)=0.71, p=0.49)$. However, the CORT response peaked earlier and decayed more rapidly in running mice. CORT levels in running mice were elevated compared with sedentary mice following $20 \mathrm{~min}$ of restraint $(t(14)=3.70$, $p<0.01)$. Levels of CORT following restraint stress decayed to baseline in running mice at $120 \mathrm{~min}(t(22)=-1.87$, $p=0.08$ ). In contrast to running mice, CORT levels in sedentary mice remained elevated above baseline levels at $120 \min (t(22)=3.52, p<0.01)$.

Body, adrenal, and thymus weights. Body weight did not differ between running and sedentary mice. A significant difference in total adrenal weight (normalized for body weight) was observed between running and sedentary mice
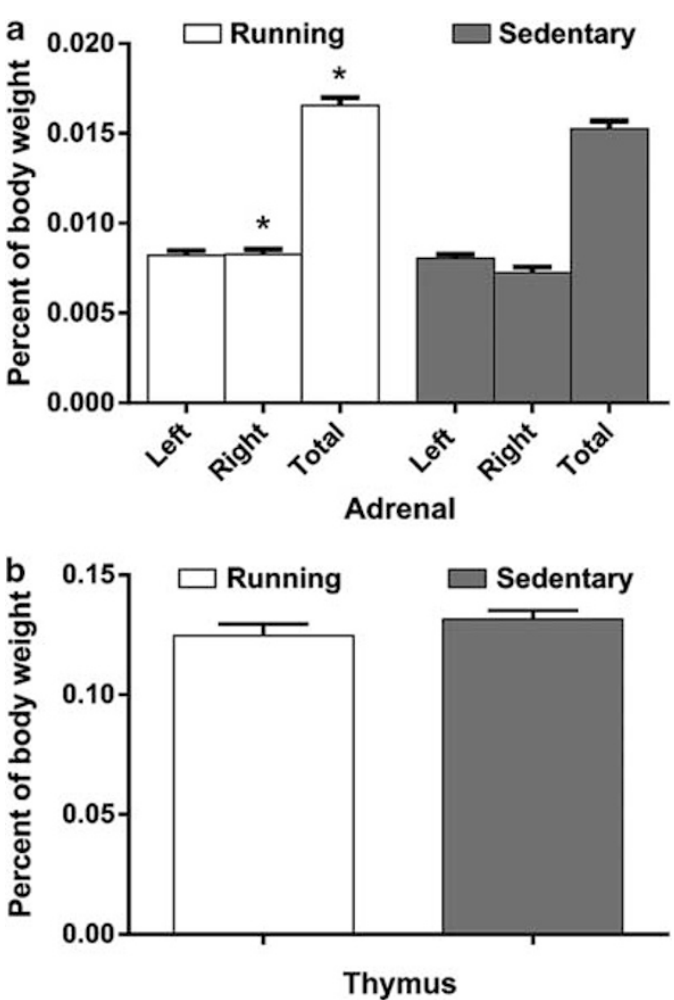

Figure 3 (a) Adrenal and (b) thymus weights following 28 days of wheel running $(\mathrm{mg} \pm \mathrm{SEM})$. Total and right adrenal weights (normalized to body weight) were elevated in running mice compared with sedentary controls. Thymus weights were similar in running and sedentary mice. $* p<0.05$ in comparison with sedentary animals.

$(t(71)=2.06, p<0.05)$, an effect that was driven by an increase in the size of the right adrenal $(t(71)=2.36$, $p<0.05$, Figure 3a). No difference in left adrenal size was observed between groups. There were no differences in thymus weights between running and sedentary mice (Figure $3 \mathrm{~b}$ ). These findings are consistent with the results of others in demonstrating that wheel running in C57BL/6J mice produces adrenal enlargement consistent with HPAaxis activation (Droste et al, 2003) without the thymal involution typically observed alongside adrenal enlargement in stressed animals (Bhatia et al, 2011; Kour and Bani, 2011; Réus et al, 2012).

Active-phase CORT. No differences in the CORT response were observed between running and sedentary mice (Figure 4). CORT samples obtained at ZT12 on days 14 and 28 were similar in running and sedentary mice (group, $\mathrm{F}(1,14)=0.73, p=0.41$, day, $\mathrm{F}(1,14)=0.308, p=0.59$, day $\mathrm{X}$ group, $\mathrm{F}(1,14)=2.06, p=0.17$, Figure $4 \mathrm{a})$. CORT levels observed $1 \mathrm{~h}$ into the active period were similar in running and sedentary mice on days 14 and 28 of wheel access (group, $\mathrm{F}(1,14)=0.37, p=0.55$, Figure $4 \mathrm{~b}$ ). An effect of day $(\mathrm{F}(1,14)=7.41, p<0.05)$, was observed in mice sampled at ZT13. The main effect of the day did not interact with group (day $\mathrm{X}$ group, $\mathrm{F}(1,14)=0.02, p=0.90$ ) suggesting that the decrease in CORT observed on day 28 in the mice sampled at ZT13 was consistent across both levels of group. Thus, no difference in CORT at the onset of the active phase was observed between running and sedentary mice. 

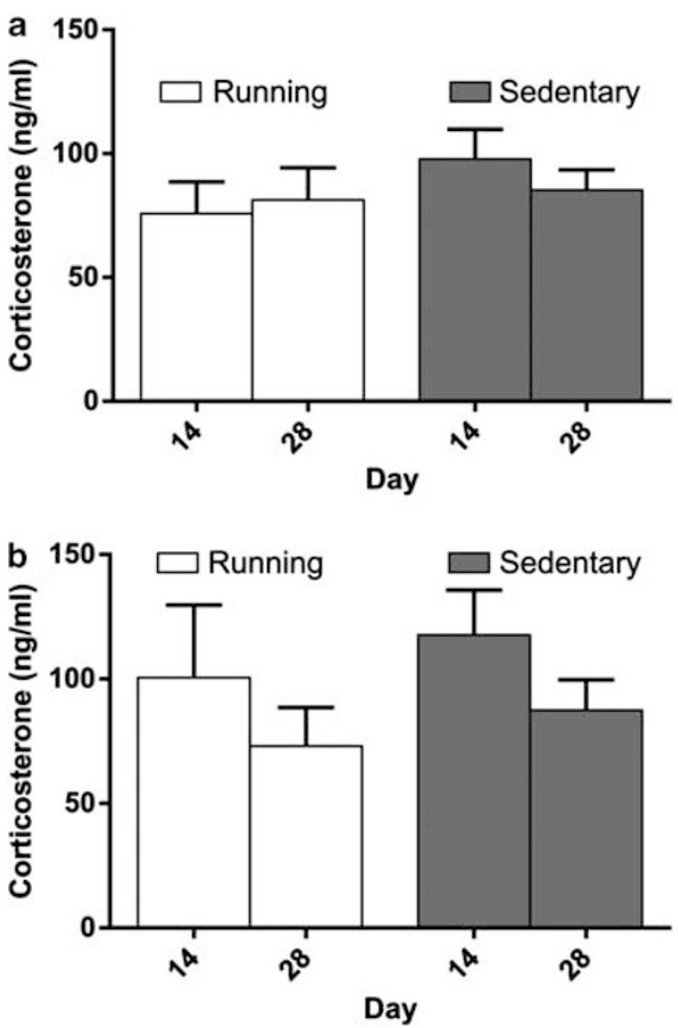

Figure 4 (a) ZTI2 and (b) ZTI3 corticosterone samples following 14 and 28 days of wheel running $(\mathrm{ng} / \mathrm{ml} \pm$ SEM). Corticosterone at the onset of the active phase did not differ between running and sedentary mice at any sample point.

\section{Experiment 2}

Acoustic startle. As in Experiment 1, wheel access resulted in reduced startle amplitude. Significant effects of startle day $(\mathrm{F}(2,180)=23.97, \quad p<0.001)$, and group $(\mathrm{F}(1,90)=5.35$, $p<0.05$ ) were observed. A significant interaction (day $\mathrm{X}$ group $\mathrm{F}(2,180)=6.30, p<0.01$ ) was supported by reduced startle amplitude in running mice at day $14(t(45)=7.07$, $p<0.001)$, and $28(t(45)=4.87, p<0.001)$ when compared with baseline.

Peripheral DST. Systemic dexamethasone suppressed endogenous CORT equally in both running and sedentary mice (Figure 5). A significant effect of dose was observed following peripheral dexamethasone injection $(\mathrm{F}(2,60)=24.95$, $p<0.001$, Figure 5). The effect of dose was apparent in both groups (dose $\mathrm{X}$ group, $\mathrm{F}(2,60)=0.73, p=0.49$, group, $\mathrm{F}(1,30)=0.00, p=0.99)$ and was evident as a reduction in plasma CORT when mice were administered the $0.05 \mathrm{mg} / \mathrm{kg}$ dose $(0.05 \mathrm{mg} / \mathrm{kg}$ v. vehicle, exercise, $t(15)=4.89, p<0.001$, sedentary, $t(14)=7.06, p<0.001)$. The intermediate dose of dexamethasone produced similar results (Figure 5 inset). A significant effect of dose was evident $(\mathrm{F}(2,26)=12.19$, $p<0.001)$ although a supporting interaction was not present (dose $\mathrm{X}$ group, $\mathrm{F}(2,26)=0.25, p=0.78$ ), nor was an effect of wheel access designation (group $\mathrm{F}(1,13)=2.06, p=0.18$ ).

Central DST. Central dexamethasone suppressed endogenous CORT equally in both running and sedentary mice (Figure 6). ICV dexamethasone injection resulted in a

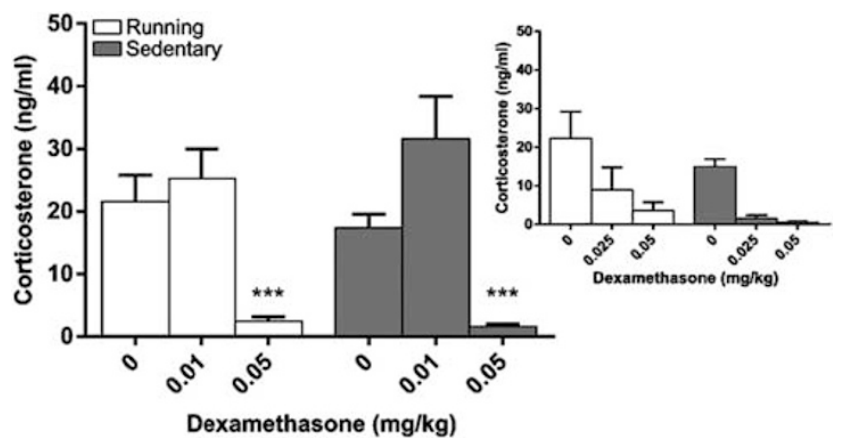

Figure 5 Mean plasma corticosterone $(\mathrm{ng} / \mathrm{ml} \pm$ SEM) response following ip dexamethasone administration in running and sedentary mice following 28 days of wheel access. Plasma corticosterone was reduced similarly in running and sedentary mice at the highest dose of dexamethasone $(0.05 \mathrm{mg} / \mathrm{kg})$. Administration of an intermediate dose of dexamethasone $(0.025 \mathrm{mg} / \mathrm{kg})$ did not produce divergent results (inset). **** $p<0.00 \mathrm{l}$ in comparison with respective $0 \mathrm{mg} / \mathrm{kg}$ dose.

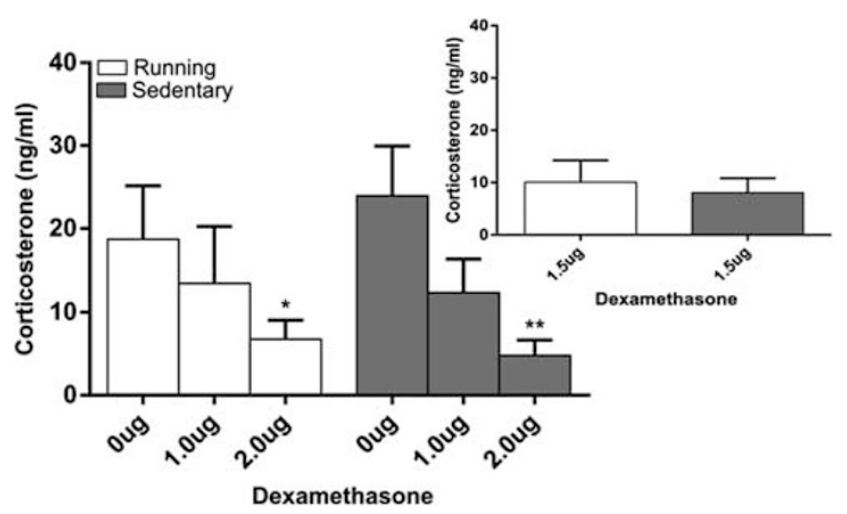

Figure 6 Mean plasma corticosterone $(\mathrm{ng} / \mathrm{ml} \pm \mathrm{SEM}$ ) response following ICV dexamethasone administration in running and sedentary mice following 28 days of wheel access. Dexamethasone $2 \mathrm{ng}$ resulted in reduced corticosterone in running and sedentary mice. Administration of an intermediate dose of dexamethasone $(750 \mathrm{ng} / \mathrm{ml})$ did not produce divergent results (inset). $* p<0.05$, $* * p<0.01$ in comparison with respective 0 ng dose.

significant reduction in plasma CORT (dose, $\mathrm{F}(2,53)=7.47$, $p<0.001$, Figure 6). The reduction in plasma CORT was evident in both groups (dose $\mathrm{X}$ group, $\mathrm{F}(2,53)=0.42$, $p=0.66$, group, $\mathrm{F}(1,53)=0.05, p=0.83)$. The $2 \mathrm{ng}$ dexamethasone dose produced a significant reduction in plasma CORT when compared with vehicle injection in running $(t(20)=2.1, p<0.05)$ and sedentary $(t(20)=3.71, p<0.01)$ animals. Similarly, there was no difference in suppression between running and sedentary mice at a second more intermediate ( $1.5 \mathrm{ng}, t(14)=0.40, p=0.69)$ dose suggesting that the lack of a group effect is not attributable to selection of doses on the extremes of the dose-response curve (Figure 6 inset).

\section{Experiment 3}

Acoustic startle. As in experiments 1 and 2, running resulted in reduced startle amplitude. An effect of startle day $(\mathrm{F}(2,54)=6.28, p<0.01)$ was observed, that was qualified by a significant interaction (day $\mathrm{X}$ group, $\mathrm{F}(2,54)=3.34$, $p<0.05)$. A significant reduction in startle amplitude was evident at day $28(t(14)=3.17, p<0.01)$ in running mice. 


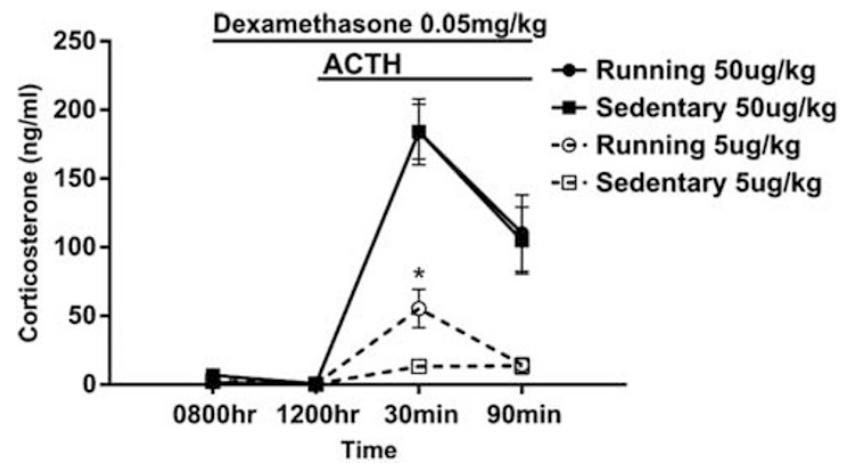

Figure 7 Mean plasma corticosterone $(\mathrm{ng} / \mathrm{ml} \pm \mathrm{SEM})$ response following ACTH administration in running and sedentary mice. Adrenal sensitivity was similar following $50 \mu \mathrm{g} / \mathrm{kg}$ ACTH administration. In contrast, running animals demonstrated enhanced sensitivity to ACTH after administration of $5 \mu \mathrm{g} / \mathrm{kg}$ ACTH. ${ }^{*} p<0.05$ running in comparison with sedentary at $5 \mu \mathrm{g} / \mathrm{kg}$ dose.

Adrenal sensitivity. Exogenous ACTH administration resulted in greater plasma CORT in running mice suggesting increased adrenal sensitivity following 4 weeks of wheel access (Figure 7). A significant effect of time was observed following administration of $50 \mu \mathrm{g} / \mathrm{kg} \operatorname{ACTH}(\mathrm{F}(3,42)=71.11$, $p<0.001)$. However, an interaction was not apparent (time $\mathrm{X}$ group, $\mathrm{F}(3,42)=0.04, \quad p=0.99$, group, $\mathrm{F}(1,14)=0.00$, $p=0.99$ ). In contrast to the effect of high-dose ACTH, running and sedentary mice demonstrated different sensitivity to low-dose $(5 \mu \mathrm{g} / \mathrm{kg})$ ACTH. A significant interaction suggested that running mice were more sensitive to exogenous ACTH administration (time $\mathrm{F}(3,42)=15.45$, $p<0.001$, group $(\mathrm{F}(1,14)=6.28, p<0.05$, time $\mathrm{X}$ group, $\mathrm{F}(3,42)=6.9, p<0.01)$. Running mice produced a larger elevation in plasma CORT $30 \mathrm{~min}$ after ACTH injection $(t(14)=2.93, p<0.05)$.

\section{DISCUSSION}

Voluntary wheel running in mice resulted in an altered CORT response to stress. Following $30 \mathrm{~min}$ of restraint, the CORT level was not different in wheel-running and sedentary mice. However, wheel-running mice reached peak CORT levels significantly faster than sedentary mice and subsequently reached baseline CORT levels more quickly following termination of the stressor. The earlier time to peak CORT may have been the consequence of increased adrenal sensitivity, and wheel-running mice showed larger adrenal size and an enhanced CORT response to exogenous ACTH administration. However, despite the observation that the CORT response to stress was shorter lived in wheel-running mice, we did not observe changes in either peripheral or central HPA-axis negative feedback.

Consistent with previous work from our laboratory (Fox et al, 2008; Salam et al, 2009), wheel running was associated with reduced anxiety-like behavior. However, it was unclear whether the observed changes in the HPA axis actually contributed to the anxiolytic effect of wheel running. The HPA-axis changes may be a consequence of the reduced anxiety following wheel running that results from runninginduced changes in central anxiety circuits. Alternatively, the altered HPA-axis function and reduced anxiety-like behavior may be mediated by independent mechanisms following wheel running. However, the fact that stress prior to the onset of wheel running interferes with both the anxiolytic effect of wheel running (Hare et al, 2012) and, in an HPA-axis-dependent fashion, the running-associated increase in neurogenesis (Stranahan et al, 2006) suggests that HPA-axis activation and the effects of wheel running are linked. More research is needed to understand the role of the HPA-axis in the beneficial effects of wheel running.

Unlike previous studies (Adlard and Cotman, 2004; Droste et al, 2003; Fediuc et al, 2006; Stranahan et al, 2006), we did not observe a running-induced increase in CORT in the early stages of the active phase. Although several studies have shown increased CORT at the onset of the active period in wheel-running rodents, it is unclear whether this increase reflects a true increase in CORT (ie, an increase in peak CORT), or an activity-dependent CORT release. Indeed, Girard and Garland (2002) showed that wheel running immediately prior to blood sampling positively predicted plasma CORT concentration. It is important to note that mice in the current study were group housed, whereas studies demonstrating increased active-phase CORT were conducted on individually housed animals. Thus, it is reasonable to expect that each animal with wheel access in an individually housed condition was engaged in wheel running just prior to sampling. However, in the group housing conditions used in the current study, we cannot be certain that each mouse was engaged in wheel running preceding the sample period. Indeed, we have shown that although mice share the running wheel over the course of the $12 \mathrm{~h}$ active phase, individual mice tend to occupy the wheel for very brief $(<30 \mathrm{~s})$ epochs of time over the course of the $12 \mathrm{~h}$ (Salam et al, 2009). Thus, it is possible that an activity-induced increase in CORT at the onset of the active phase was washed out either by sampling mice within the cage that had not recently run or that had run for a very short period of time. Nevertheless, our data indicate that wheel running is not universally associated with an increase in active-phase peak diurnal CORT.

Consistent with previous reports, wheel running was associated with an increase in adrenal size (Campeau et al, 2010; Droste et al, 2007; Droste et al, 2003; Droste et al, 2006; Nyhuis et al, 2010; Sasse et al, 2008). Several studies have shown that stress-induced ACTH release is similar, or reduced, in wheel-running rodents when compared with sedentary controls (Droste et al, 2007; Droste et al, 2003; Fediuc et al, 2006; but see Campeau et al, 2010). In the present report, the rapid stress-induced peak CORT response and the augmented response to low-dose ACTH, suggested a wheel running-associated enhancement in adrenal sensitivity that was consistent with the increased adrenal size in wheel-running mice. However, it is important to note that adrenal enlargement does not always lead to increased sensitivity to ACTH. Studies have shown that chronic stress (Michopoulos et al, 2012; Reber et al, 2007; Uschold-Schmidt et al, 2012) and GR mutations (Karanth et al, 1997) result in adrenal hypertrophy but reduced CORT release following ACTH challenge. Thus, the increased adrenal sensitivity observed here may represent an adaptive change that allows mice with wheel access to mount a more rapid response when exposed to a challenge that results in ACTH release. 
We did not find evidence for enhanced negative feedback in wheel-running mice using the DST either peripherally or centrally. One mechanism by which HPAaxis negative feedback is initiated is by GR activation in the pituitary, hippocampus, prefrontal cortex, and hypothalamus during periods of elevated CORT (Herman et al, 2005). Wheel running alters the ratio of mineralocorticoid to GR in the hippocampus in a manner that likely increases the capacity for negative feedback (Droste et al, 2007; Droste et al, 2003). However, in the current studies, the DST assessed feedback inhibition under basal CORT release conditions. It is possible that wheel runningassociated HPA-axis changes promote more rapid feedback under stress conditions. Because stress levels of CORT are achieved more rapidly in wheel-running mice, negative feedback mechanisms may be engaged more quickly resulting in more rapid termination of the CORT response as observed in Experiment 1.

Although the peak stress-induced CORT response did not differ in wheel-running and sedentary mice, the earlier peak and more rapid decay of the response suggest the possibility of a change in the pattern of CORT exposure following stress in wheel-running mice. The HPA-axis response to stressors consists of a sequence of adaptive responses that may have adverse consequences if they are inadequate, or prolonged (Charmandari et al, 2005). Rodents with wheel access typically show a more finely tuned response to stressors, mounting a more robust response than sedentary animals to those with physical components such as forced swim or restraint that would demand sufficient mobilization of energy resources (Campbell et al, 2009; Droste et al, 2007; Droste et al, 2003; Droste et al, 2006), and a more curtailed response to those that are purely psychogenic, such as loud noise or novel cage exposure that would require less energy (Campeau et al, 2010; Droste et al, 2007; Droste et al, 2003). A similar finding is observed in humans in that exercise blunts the HPA-axis response to a single exposure of oral mCPP a 5HT-2C agonist with anxiogenic properties (Broocks et al, 1999; Broocks et al, 2001). Taken together, these findings suggest that exercise may improve control over the HPA-axis response to stress, producing a more efficient response that is enhanced or diminished depending upon the nature of the stressor.

In the current study, wheel running reduced anxiety-like behavior, which was concurrent with a more rapid CORT response and CORT decay to restraint stress, increased adrenal size, and increased sensitivity to ACTH. The HPAaxis changes observed in wheel-running animals suggests that wheel running enhanced central control over the HPAaxis response to subsequent stressors. Many of the negative effects of stress are attributed to chronic exposure to elevated glucocorticoid levels (Sapolsky, 2003). Given the data reported here, and previously, it appears that wheel running renders animals particularly resilient, capable of producing a robust stress response while limiting the harm that may result from overexposure to glucocorticoids during times of stress. An understanding of the mechanisms by which running induces alterations in stress-responsive regions, and whether these changes provide resistance to the effects of glucocorticoid overexposure, are necessary to determine the utility of the running-associated changes observed here.

\section{FUNDING AND DISCLOSURE}

Drs Toufexis's, Hammack's, and Falls' works have been funded by the National Institute of Health. The project described was supported by NIH Grant Numbers 5 P30 RR032135 from the COBRE Program of the National Center for Research Resources and 8 P30 GM 103498 from the National Institute of General Medical Sciences. The other authors declare no conflict of interest.

\section{REFERENCES}

Adlard PA, Cotman CW (2004). Voluntary exercise protects against stress-induced decreases in brain-derived neurotrophic factor protein expression. Neuroscience 124: 985-992.

Bartolomucci A, Pederzani T, Sacerdote P, Panerai AE, Parmigiani S, Palanza P (2004). Behavioral and physiological characterization of male mice under chronic psychosocial stress. Psychoneuroendocrinology 29: 899-910.

Bhatia N, Jaggi AS, Singh N, Anand P, Dhawan R (2011). Adaptogenic potential of curcumin in experimental chronic stress and chronic unpredictable stress-induced memory deficits and alterations in functional homeostasis. J Nat Med 65: 532-543.

Binder E, Droste SK, Ohl F, Reul JM (2004). Regular voluntary exercise reduces anxiety-related behaviour and impulsiveness in mice. Behav Brain Res 155: 197-206.

Broocks A, Meyer T, George A, Hillmer-Vogel U, Meyer D, Bandelow B et al (1999). Decreased neuroendocrine responses to meta-chlorophenylpiperazine (m-CPP) but normal responses to ipsapirone in marathon runners. Neuropsychopharmacology 20: 150-161.

Broocks A, Meyer T, Gleiter CH, Hillmer-Vogel U, George A, Bartmann U et al (2001). Effect of aerobic exercise on behavioral and neuroendocrine responses to meta-chlorophenylpiperazine and to ipsapirone in untrained healthy subjects. Psychopharmacology (Berl) 155: 234-241.

Buck HM, Hueston CM, Bishop C, Deak T (2011). Enhancement of the hypothalamic-pituitary-adrenal axis but not cytokine responses to stress challenges imposed during withdrawal from acute alcohol exposure in Sprague-Dawley rats. Psychopharmacology 218: 203-215.

Campbell JE, Rakhshani N, Fediuc S, Bruni S, Riddell MC (2009). Voluntary wheel running initially increases adrenal sensitivity to adrenocorticotrophic hormone, which is attenuated with longterm training. J App Physiol 106: 66-72.

Campeau S, Nyhuis TJ, Sasse SK, Kryskow EM, Herlihy L, Masini CV et al (2010). Hypothalamic pituitary adrenal axis responses to low-intensity stressors are reduced after voluntary wheel running in rats. J Neuroendocrinol 22: 872-888.

Charmandari E, Tsigos C, Chrousos G (2005). Endocrinology of the stress response. Ann Rev Physiol 67: 259-284.

Cole MA, Kim PJ, Kalman BA, Spencer RL (2000). Dexamethasone suppression of corticosteroid secretion: evaluation of the site of action by receptor measures and functional studies. Psychoneuroendocrinology 25: 151-167.

Cone RD, Mountjoy KG, Robbins LS, Nadeau JH, Johnson KR, Roselli-Rehfuss L et al (1993). Cloning and functional characterization of a family of receptors for the melanotropic peptides. Ann NY Acad Sci 680: 342-363.

deKloet ER, Joëls M, Holsboer F (2005). Stress and the brain: from adaptation to disease. Nat Rev Neurosci 6: 463-475.

De Moor MHM, Beem AL, Stubbe JH, Boomsma DI, De Geus EJC (2006). Regular exercise, anxiety, depression and personality: a population-based study. Prev Med 42: 273-279.

Dijkstra I, Binnekade R, Tilders FJ (1996). Diurnal variation in resting levels of corticosterone is not mediated by variation in 
adrenal responsiveness to adrenocorticotropin but involves splanchnic nerve integrity. Endocrinology 137: 540-547.

Droste SK, Chandramohan Y, Hill LE, Linthorst ACE, Reul JM (2007). Voluntary exercise impacts on the rat hypothalamicpituitary-adrenocortical axis mainly at the adrenal level. Neuroendocrinology 86: 26-37.

Droste SK, Gesing A, Ulbricht S, Muller MB, Linthorst ACE, Reul JM (2003). Effects of long-term voluntary exercise on the mouse hypothalamic-pituitary-adrenocortical axis. Endocrinology 144: 3012-3023.

Droste SK, Schweizer MC, Ulbricht S, Reul JM (2006). Long-term voluntary exercise and the mouse hypothalamic-pituitary-adrenocortical axis : impact of concurrent treatment with the antidepressant drug tianeptine. J Neuroendocrinol 18: 915-925.

Dunn AL, Trivedi MH, O’Neal HA (2001). Physical activity doseresponse effects on outcomes of depression and anxiety. Med Sci Sports Exerc 33: S587-S597.

Fediuc S, Campbell JE, Riddell MC (2006). Effect of voluntary wheel running on circadian corticosterone release and on HPA axis responsiveness to restraint stress in Sprague-Dawley rats. J Appl Physiol 100: 1867-1875.

Fox JH, Hammack SE, Falls WA (2008). Exercise is associated with reduction in the anxiogenic effect of $\mathrm{mCPP}$ on acoustic startle. Behav Neurosci 122: 943-948.

Girard I, Garland T Jr. (2002). Plasma corticosterone response to acute and chronic voluntary exercise in female house mice. J Appl Physiol 92: 1553-1561.

Greenwood BN, Foley TE, Burhans D, Maier SF, Fleshner M (2005). The consequences of uncontrollable stress are sensitive to duration of prior wheel running. Brain Res 1033: 164-178.

Greenwood BN, Foley TE, Day HEW, Campisi J, Hammack SH, Campeau S et al (2003). Freewheel running prevents learned helplessness/behavioral depression: role of dorsal raphe serotonergic neurons. J Neurosci 23: 2889-2898.

Groenink L, Dirks A, Verdouw PM, Ml Schipholt, Veening JG, van der Gugten J et al (2002). HPA axis dysregulation in mice overexpressing corticotropin releasing hormone. Biol Psychiatry 51: 875-881.

Han ES, Evans TR, Nelson JF (1998). Adrenocortical responsiveness to adrenocorticotropic hormone is enhanced in chronically food-restricted rats. J Nutr 128: 1415-1420.

Hare BD, D'Onfro KC, Hammack SE, Falls WA (2012). Prior stress interferes with the anxiolytic effect of exercise in c57bl/6j mice. Behav Neurosci 126: 850-856.

Herman JP, Ostrander MM, Mueller NK, Figueiredo H (2005). Limbic system mechanisms of stress regulation: hypothalamopituitary-adrenocortical axis. Prog Neuropsychopharmacol Biol Psychiatry 29: 1201-1213.

Herring MP, O'Connor PJ, Dishman RK (2010). The effect of exercise training on anxiety symptoms among patients: a systematic review. Arch Intern Med 170: 321-331.

Holsboer F (2001). Stress, hypercortisolism and corticosteroid receptors in depression: implicatons for therapy. J Affect Disorder 62: 77-91.

Karanth S, Linthorst AC, Stalla GK, Barden N, Holsboer F, Reul JM (1997). Hypothalamic-pituitary-adrenocortical axis changes in a transgenic mouse with impaired glucocorticoid receptor function. Endocrinology 138: 3476-3485.

Kellner M, Baker DG, Yehuda R (1997). Salivary cortisol and PTSD symptoms in Persian Gulf war combatants. Ann NY Acad Sci 821: $442-443$.

Kour K, Bani S (2011). Augmentation of immune response by chicoric acid through the modulation of CD28/CTLA-4 and Th1 pathway in chronically stressed mice. Neuropharmacology 60: 852-860.

Lawlor DA, Hopker SW (2001). The effectiveness of exercise as an intervention in the management of depression: systematic review and meta-regression analysis of randomised controlled trials. BMJ 322: 763-767.

Michopoulos V, Reding KM, Wilson ME, Toufexis D (2012). Social subordination impairs hypothalamic-pituitary-adrenal function in female rhesus monkeys. Horm Behav 62: 389-399.

Nyhuis TJ, Masini CV, Sasse SK, Day HEW, Campeau S (2010). Physical activity, but not environmental complexity, facilitates HPA axis response habituation to repeated audiogenic stress despite neurotrophin mRNA regulation in both conditions. Brain Res 1362: 68-77.

Otsuka T, Goto M, Kawai M, Togo Y, Sato K, Katoh K et al (2012). Photoperiod regulates corticosterone rhythms by altered adrenal sensitivity via melatonin-independent mechanisms in Fischer 344 rats and C57BL/6J mice. PloS One 7: 6.

Pelleymounter MA, Joppa M, Carmouche M, Cullen MJ, Brown B, Murphy B et al (2000). Role of corticotropin-releasing factor (CRF) receptors in the anorexic syndrome induced by CRF. J Pharmacol Exp Ther 293: 799-806.

Reber SO, Birkeneder L, Veenema AH, Obermeier F, Falk W, Straub RH et al (2007). Adrenal insufficiency and colonic inflammation after a novel chronic psycho-social stress paradigm in mice: implications and mechanisms. Endocrinology 148: 670-682.

Réus GZ, Abelaira HM, Stringari RB, Fries GR, Kapczinski F, Quevedo J (2012). Memantine treatment reverses anhedonia, normalizes corticosterone levels and increases BDNF levels in the prefrontal cortex induced by chronic mild stress in rats. Metab Brain Dis 27: 175-182.

Risbrough VB, Hauger RL, Roberts AL, Vale WW, Geyer MA (2004). Corticotropin-releasing factor receptors CRF1 and CRF2 exert both additive and opposing influences on defensive startle behavior. J Neurosci 24: 6545-6552.

Robertson J, Curley J, Kaye J, Quinn J, Pfankuch T, Raber J (2005). apoE isoforms and measures of anxiety in probable $\mathrm{AD}$ patients and Apoe - I- mice. Neurobiol Aging 26: 637-643.

Salam JN, Fox JH, Detroy EM, Guignon MH, Wohl DF, Falls WA (2009). Voluntary exercise in C57 mice is anxiolytic across several measures of anxiety. Behav Brain Res 197: 31-40.

Sapolsky RM (2003). Stress and plasticity in the limbic system. Neurochem Res 28: 1735-1742.

Sasse SK, Greenwood B, Masini CV, Nyhuis TJ, Fleshner M, Day HEW et al (2008). Chronic voluntary wheel running facilitates corticosterone response habituation to repeated audiogenic stress exposure in male rats. Stress 11: 425-437.

Sciolino NR, Dishman RK, Holmes PV (2012). Voluntary exercise offers anxiolytic potential and amplifies galanin gene expression in the locus coeruleus of the rat. Behav Brain Res 233: 191-200.

Stranahan AM, Khalil D, Gould E (2006). Social isolation delays the positive effects of running on adult neurogenesis. Nat Neurosci 9: $526-533$.

Uschold-Schmidt N, Nyuyki KD, Füchsl AM, Neumann ID, Reber SO (2012). Chronic psychosocial stress results in sensitization of the HPA axis to acute heterotypic stressors despite a reduction of adrenal in vitro ACTH responsiveness. Psychoneuroendocrinology 37: 1676-1687.

Yehuda R, McFarlane AC, Shalev AY (1998). Predicting the development of posttraumatic stress disorder from the acute response to a traumatic event. Biol Psychiatry 44: 1305-1313. 